sending medicines, be obliged to attach to each article a printed label, denoting its name, the place whence it was issued, by whom prescribed, the dose, the time it was delivered, and to whom it was delivered? This would render it casy to txace when and to whom medicines were delivered, and would often he of incal. culable advantage in our courts of law in cases in which potent medicines or poisons have been dispensed, by shortening or avouding long and porplexing inves. tigations. Some years ago 1 read an excellent article on this subject (as the common practice of Russia), I think from the pen of Dr. Granville. Another point amongst the dreadful abuse of remedial means by quacks, is that of fumigating baths, both in and out of London, which with one exception perhaps have no preterisions to corectness of principle or proper management. A public fumigating establishrient requires the exclusive attention of a well-educated physician; and none other are allowed to keep them on the continent. Thus, means which there are found to be of the greatest benefit in the treatment of severe diseases, is lost here to the profession and the public, from want of being understood and properly conducted. I am, Sir, your obedient servant,

Sexagenarius.

\section{INFIRMARY AT AYLESBURY.} MORE NEPOTISM.

\section{To the Elitor of The Lancet.}

SIR,-An infirmary, containing forty beds, has recently been established at Aylesbury, and from some circumsiances which have occurred, a great deal of excitement has been produced in the medical crrcle of that town. It appears that $\mathrm{Dr}$. Edmonds, surgeon, R.N., an Aberdeen diplomatist, was appointed physician to this new institution, and four surgeons residing in the town were to take the susgical department. Things, however, were not to go on so smoothly and quietly as the latter gentlemen anticipated, for since their appoirtment they were told by one of great influence in Aylesbury, that Mr. Bransis Cooper was chosen consulting surgeon, that he would visit them once in every three months, and that all operations were to be performed by him, or at least have his sanction. This communication was received with surprise and indignation; but there was no alternative, and the surgets", to get out of the dilemma, determined to have a consulting physician. They applied to Dr. Bilinng of the London Hospital, but who, with feelings highly creditable to his professional ch aracter, declined having any connexion with the new establishment. I am really at a loss to understand what benefit could accrue to the patients from a physician or a surgeon seeing them once in three months, and $I$ am sure it only requires the application of THE LANCET to do away with such ridiculous and de. grading appointments.

I am, Sir, yours obediently,

J. Birtwistle.

Mile-End Road, July 29th, 1833 .

\section{THE CHOLERA.-MEDICAL ASSISTANTS.}

To the Editor of THe Lancet.

Sir,-However painful it must he to perceive the announcement contained in a late LANCET of the reappearance of the cho. lera in this country, it behores us all to do everything in our power to counteract and assuage this epidemic enemy. I therefore wish to draw your attention, and, if as. senting, to beg your aid and support as a liberal journalist and a philanthropic man, to an intention I formerly had in view, but at too late a period of the late attack of cholera, to be then put in practice.

I should propose an association to be formed of all the young unemployed medical assistants in the metropolis; so that at a moment's notice any medical gentleman, family, or others, could procure a competent person to superinterd the nursery department of the sick.

'Three objects would be gained by this project: the (almost innumerable) unemployed assistants woull gain employment, medical men would be able to give their directions with greater confidence of their heing perserered in, and most of all, many lives would be saved.

Having witnessed, during its late prevalence, many cases, both of the malignant species and the premonitory symptoms of cholera, in which a fatal ternination ensued in consequence of a want of attention,-I say that in every case of cholera a medical man onght to be at the bed-side of the patient, for having seen the multifarious remedies made use of, from the calomel and laudanum of Asia to the chromate of potash and venous transfision of the Scotch, I have no hesitation in saying that every case requires variety of treatment, and great discretionary power must necessarily remain with the chief nurse.

Trusting the idea will meet your approbation, and that when I come up to town 